See discussions, stats, and author profiles for this publication at:

https://www.researchgate.net/publication/220591795

\title{
Impacts of End-User and Information Center Characteristics on End-User Computing Support
}

Article in Journal of Management Information Systems · June 1994

CITATIONS

60
READS

115

2 authors, including:

\section{Rajesh Mirani}

University of Baltimore

28 PUBLICATIONS 550 CITATIONS

SEE PROFILE

Some of the authors of this publication are also working on these related projects:

Project (To be Decided) View project

All content following this page was uploaded by Rajesh Mirani on 03 April 2015. 


\title{
Impacts of End-User and Information Center Characteristics on End-User Computing Support
}

\author{
RAJESH MIRANI AND WILLIAM R. KING
}

RAJESH MRAN is Assistant Professor in the Information and Quantitative Sciences Department, Merrick School of Business, University of Baltimore. His research interests focus on the management of end-user computing, and the justification of proposed information systems projects. His papers have been published in MIS Quarterly, Journal of Systems Management, and Journal of End User Computing. He is also a frequent contributor to professional conferences.

WILLIAM R. KING is University Professor in the Katz Graduate School of Business at the University of Pittsburgh. He is the author of more than a dozen books and 200 papers that have appeared in the leading journals in management science and information systems. He has served as President of the Institute of Management Sciences (TIMS), as Senior Editor of the MIS Quarterly and as General Chair of the International Conference on Information Systems (ICIS).

ABSTRACT: In a cross-sectional survey of 114 information centers, it was found that support needed by end-users varied with their computing sophistication and the maturity of the information center. However, information centers did not take into account differences among users in designing support services, and provided all users with the same arnount of support. For most users, the support provided was far less than the support needed, but end-user satisfaction was higher when more support needs were fulfilled. The implication of these results is that information centers are not making the requisite effort to identify and fulfill the support needs of their end-users.

KEY WORDS AND PHRASES: end-user computing, information center, user-developed applications, user satisfaction.

A RECENT NATIONAL SURVEY OF PUBLIC SECTOR MANAGERS in federal, state, and county agencies ranked end-user computing (EUC) as one of the five most important information systems issues [13]. EUC, when properly managed, is widely believed to result in vastly improved organizational productivity, but improperly managed EUC can generate dysfunctional and even devastating consequences for an organization. EUC is best managed by balancing end-user support with appropriate controls. The notion of support entails the provision of various kinds of assistance to users in their

Journal of Management Information Systems / Summer 1994, Vol. 11, No. 1, pp. 141-166 Copyright O M.E Sharpe, Inc., 1994 
computing activities. Controls seek to provide limits, rules, and regulations for such activities.

This article focuses on support. It reports the results of a survey of information centers (ICs) conducted to examine how support needed by end-users varies with end-user computing sophistication and IC maturity. It also reports how support needed by end-users compares with support provided to them by ICs, and how the fulfillment of support needs influences end-user satisfaction.

The rest of this article is organized as follows. First, a literature review justifies this study and leads to the hypotheses. Following this, the constructs to be studied are operationalized. Subsequently, the methodology used is described, and some descriptive statistics for respondents are presented. Next, the operational measures of various constructs are statistically validated. After this, the results from the tests of hypotheses are presented. Finally, the implications of the results for information systems practitioners and researchers are discussed.

\section{Literature Review and Hypotheses}

\section{Justification for Study}

PREVIOUS RESEARCH STUDIES FOCUSING ON END-USERS have concluded that providing end-user support is one of the best means of ensuring user satisfaction $[4,8,9,44]$. Studies of information systems (IS) and IC managers have yielded similar conclusions $[30,34,45]$. Thus, end-user support is seen to be critical to user satisfaction and EUC effectiveness, and hence, to organizational effectiveness. Further, end-users consider ICs to be their most important source of support $[3,10,20]$. Since end-user support is so important and the IC is the primary mechanism in many organizations for providing end-user support, a major responsibility of IC staffs is to accurately assess and fulfill the diverse support needs of their end-users. The discussion below seeks to generate hypotheses that link diversity in end-user support needs to differences in end-user computing sophistication and IC maturity.

\section{Hypotheses}

One possible cause of diversity in the support needs of end-users is differences in their computing sophistication. For instance, Rockart and Flannery [47] conclude that:

Diversity in the end-user population also surfaces an evident need for strongly differentiated education, training, and support for the quite different classes of users. [p. 778]

Leitheiser and Wetherbe [31] suggest that the "sophistication of the users" should be taken into account by end-user managers in their selection of appropriate "service support levels." Similarly, Kasper and Cervany [25] state that more sophisticated end-users are likely to need more training than less sophisticated users. Likewise, links between end-user computing sophistication and support needed have been hypothe- 
sized in the contexts of EUC standards and policies [40], the selection of end-user applications [31], and training in application development $[2,28]$. Each of these contexts can be said to be a subset of the overall construct of end-user support.

From the discussion above, we expect support needed to vary significantly with end-user computing sophistication. A null hypothesis may therefore be stated as follows:

Null Hypothesis 1: Support needed by end-users does not vary significantly with end-user computing sophistication.

The link between IC maturity and support needed is also strongly suggested in the EUC literature. It has been proposed that EUC in any organization goes through various phases, or stages of growth, in which the needs of users dramatically change $[5,21,22,35,37]$. Magal [33] describes the increase in end-users' support needs as an IC progresses through various stages:

During the initiation stage ... users generally tend to be self-motivated and place few demands on the IC.... The number and variety of users increases, placing a greater demand on IC services both in terms of the number of requests and the level of expertise needed to respond to these requests. . . During [the formalization] stage ... user skills are relatively high, placing demands on IC staff to possess a very high level of expertise. [p. 41]

Similarly, Huff et al. [22] state that:

applications become more sophisticated as time passes ... EUC organizational training, support and managerial activities are thus driven by individuals striving to acquire new skills and solve problems by developing more complex and mature applications. [p. 543]

This suggests that support needed may vary significantly with IC maturity. Therefore, a second null hypothesis may be stated as follows:

Null Hypothesis 2: Support needed by end-users does not vary significantly with IC maturity.

The third objective of this study was to compare support needed by end-users with support provided to them by ICs. This objective results in the following null hypothesis:

Null Hypothesis 3: Support provided to users is not significantly different from the support needed by them.

The final objective of this study was to test directly whether fulfilling end-users' support needs indeed enhances overall end-user satisfaction. Several research studies have suggested that the provision of appropriate end-user support is among the most effective methods of ensuring overall user satisfaction with EUC in an organization.

For instance, Amoroso and Cheney [4] reported from a survey of end-users in large organizations that perceived organizational support of EUC was indirectly related to improved user information satisfaction. Bergeron and Berube [8] found that microcomputer end-users were more satisfied with their computing activities when there 
was an IC to support end-users. In a survey of ICs, Bergeron et al. [9] found that the proximity and variety of IC services were positively correlated with dimensions of end-user satisfaction. Rivard [44] identified six factors that contribute to end-user satisfaction. Of these, "support provided to end-users" had the highest correlation with user satisfaction.

Information systems professionals also recognize the importance of end-user support. Lederer and Spencer [30] concluded from interviews of IC managers that providing ongoing support to end-users improves IC effectiveness. Magal and Carr [34] surveyed IC managers to identify critical success factors (CSFs) for ICs. "Quality of support services" was found to be the most important of all CSFs, regardless of user and IC characteristics. Rivard and Huff [45] found that DP managers define the success of user-developed applications (UDA) as the ability to demonstrate that users are satisfied with the support made available to them.

Thus, a fourth null hypothesis may be stated as follows:

Null Hypothesis 4: End-user satisfaction does not vary significantly with fulfillment of support needs.

The measurement of "fulfillment of support needs" in Null Hypothesis 4 is described in the section reporting the results of this study. The other constructs of interestnamely, end-user support, end-user computing sophistication, IC maturity, and enduser satisfaction-are operationalized in the next section.

\section{Operationalization of Constructs}

\section{End-User Support: Needed and Provided}

THERE IS NO COMMONLY ACCEPTED MEASURE AMONG IS researchers for assessing end-user support. Since this study revolved around end-user support, a measure for this construct was developed using the method suggested by Loevinger [32]. First, the EUC literature was thoroughly researched to identify all potential support services or types of support. A long list consisting of these services (henceforth referred to as items) was constructed, with care taken to avoid overlaps or redundancies.

Following this, five academic experts in the field were asked individually to examine the list and to suggest changes. They were informed that they were free to add, delete, or change items. A few minor changes were proposed by them, and the list was revised. This revised list was individually pretested with five IS executives in five different business organizations in the Pittsburgh area. Except for a few semantic changes, all agreed that the list was exhaustive and consisted of mutually exclusive items. Based on the suggested wording changes, a modified list was prepared. This modified list consists of 54 items, and is presented in Table 1. Most items in this list find mention in several references in the EUC literature. For the sake of brevity, however, this table indicates only one reference as a primary source for each item.

Against each of the 54 items, two seven-point Likert-type scales, each ranging from "low" to "high," were provided to end-users participating in the study. On the first 
scale, they were asked to indicate the extent to which they perceived a need for the type of support described by the item, regardless of whether or not this type of support was being provided to them by the IC. On the second scale, users were asked to indicate the extent to which they perceived that the type of support described by the item was being provided to them by the IC, regardless of the extent of their need for that type of support.

\section{End-User Computing Sophistication}

End-user compuling sophistication was operationalized by two different methods in this study. The first method used Rockart and Flannery's scheme for classifying end-users into categories [47]. According to their scheme, there are four types of users (two of their six categories depict IS professionals). Nonprogramming end-users access computerized data through a limited, menu-driven environment or a strictly followed set of procedures, and use software provided by others. Command-level users perform inquiries and simple calculations and generate unique reports for themselves. End-user programmers utilize both command and programming languages to develop applications for their own personal information needs. Functional support personnel are users who, by virtue of their skills in end-user languages, become informal centers of design and programming expertise for other end-users within their functional areas.

Thus, these four categories represent points along a spectrum of EUC sophistication. In this spectrum, nonprogramming end-users are the least sophisticated users. At the other end of the spectrum, functional support personnel represent the highest levels of sophistication, although end-user programmers are often more skilled in the use of specific packages.

It should be pointed out that while other classifications of end-users have also been proposed in the EUC literature [15, 17, 36, 46], Rockart and Flannery's scheme was appropriate for this study because it uses computing sophistication or ability to classify users.

This operationalization was implemented by providing short descriptions of each category (in a sentence or two) to the end-users participating in the survey. They were asked to read these descriptions carefully and to indicate which one portrayed them most accurately. A fifth category called "other" was also included in the descriptions for users who could not readily classify themselves in the other four categories. Table 2 shows the questionnaire items used for this operationalization.

The second method by which end-user computing sophistication was operationalized was by asking users to indicate whether or not they conducted any applications development for themselves or other users. Thus, users who developed applications were rated higher in terms of computing sophistication than those who did not.

\section{IC Maturity}

IC maturity was operationalized by using a subset of Magal's instrument designed to assess the growth stage of an IC [33]. The theoretical background for this instrument 
Table 1 Measurement of EUC Support: Pool of Items

\begin{tabular}{|c|c|c|}
\hline Item & Included & Reference \\
\hline 1. & Training on uses and capabilities of end-user languages & [47] \\
\hline 2. & Training on uses and capabilities of end-user software & [44] \\
\hline 3. & Training on statistical analysis & [7] \\
\hline 4. & Training on systems analysis & {$[7]$} \\
\hline 5. & Training on application selection and cost justification & [21] \\
\hline 6. & Training on tool/product selection for application & [44] \\
\hline 7. & Training on application development methodologies & [1] \\
\hline 8. & Training on application testing/debugging & [41] \\
\hline 9. & Training on application documentation & [6] \\
\hline 10. & Training on application maintenance & [1] \\
\hline 11. & Training on backups/security & [42] \\
\hline 12. & Training on data integrity/validation & [40] \\
\hline 13. & Training on logical data modeling & [40] \\
\hline 14. & Training on file management and database technology & [7] \\
\hline 15. & Training on data communications & [7] \\
\hline 16. & Training on operating systems & [41] \\
\hline 17. & Training on software conversions & [7] \\
\hline 18. & Training on technology updates & [7] \\
\hline 19. & $\begin{array}{l}\text { Hardware related services (e.g., micro-mainframe links, } \\
\text { purchase, and installation, etc.) }\end{array}$ & [31] \\
\hline 20. & Providing software backup/recovery service & [31] \\
\hline 21. & Providing help facilities for software & [39] \\
\hline 22. & Supporting fourth generation languages & [14] \\
\hline 23. & Supporting a variety of other languages & [14] \\
\hline 24. & Supporting a variety of applications development software & [1] \\
\hline 25. & Conducting software demonstrations & [22] \\
\hline 26. & Listing software resources: software libraries & [1] \\
\hline 27. & Developing macros and job control statements & [14] \\
\hline 28. & Software purchase and evaluation & [50] \\
\hline 29. & Maintaining data integrity and currency & [22] \\
\hline 30. & Providing backup/recovery service & [22] \\
\hline 31. & Listing corporatewide data resources & [31] \\
\hline 32. & Providing corporate data extraction facilities & [49] \\
\hline 33. & Facilitating data sharing among users & [47] \\
\hline 34. & Maintaining subject databases & [21] \\
\hline 35. & Auditing user-developed applications & [38] \\
\hline 36. & Conducting maintenance reviews of user-developed applications & [10] \\
\hline 37. & Coordinating applications across users & [50] \\
\hline 38. & Standardization of hardware to be used & [27] \\
\hline 39. & Listing approved hardware vendors & [27] \\
\hline
\end{tabular}


Table 1 Continued

\begin{tabular}{llr}
\hline Item & \multicolumn{1}{c}{ Included } & Reference \\
\hline 40. & Outlining formal procedures for getting getting hardware purchase & {$[27]$} \\
& approved & {$[27]$} \\
41. & Establishment of communication protocols & {$[27]$} \\
42. & Standardization of programming languages & {$[27]$} \\
43. & Standardization of applications development software & {$[27]$} \\
44. & Standardization of operating systems & {$[1]$} \\
45. & Establishment of guidelines for systems analysis, design, & \\
& testing, documentation, and maintenance & {$[1]$} \\
46. & Establishment of guidelines for software backups & {$[7]$} \\
47. & Listing approved software vendors & {$[22]$} \\
48. & Outlining formal procedures for getting software purchase & {$[1]$} \\
& approved & {$[1]$} \\
49. & Establishment of standards for data backup & {$[40]$} \\
50. & Establishment of guidelines for use and modification of corporate \\
& data & {$[1]$} \\
51. & Delineation of end-user and staff roles & {$[5]$} \\
52. & Outlining domains for user-developed applications & {$[12]$} \\
53. & Existence of a local (departmental) support staff & \\
54. & Specialization of support staff &
\end{tabular}

was described by Magal in an earlier study [35]. According to this theory, ICs go through four stages: initiation, expansion, formalization, and maturity. Other "stages of growth" models have also been proposed in the IS literature to describe how EUC matures in an organization $[5,22,37]$. However, Magal's model has been empirically tested and validated.

Magal's instrument is designed to be administered to IC managers. Therefore, IC maturity was assessed by asking IC managers to respond to five questions regarding five key variables: IC planning procedures, control mechanisms, policies and procedures, priority criteria, and evaluation methods. In each question, IC managers were asked to read four alternate descriptions of ICs with respect to a key variable and to indicate which description best applied to their IC. Depending on the response, a score of $1,2,3$, or 4 was assigned for each of the five questions. The mean of all five scores was then computed as IC maturity, whose possible values were also between 1 and 4. Table 3 depicts the questionnaire item pertaining to one of the five key variables.

\section{End-User Satisfaction}

In IS research, user satisfaction is the most popular and commonly used surrogate for systems effectiveness $[18,19,23,24,48]$. Doll and Torkzadeh have developed an instrument for the specific context of EUC [18]. This instrument measures the "computing satisfaction" of an end-user with a specific application. However, this 
Table 2 Operationalization of End-User Computing Sophistication: Questionnaire Items

Two popular definitions of "end-user computing" are the "practice of end-users developing, maintaining, and using their own information systems" and "the capability of users to have direct control over their computing needs." Please check one of the following types of end-users which describes you most accurately.

() NONPROGRAMMING END USERS

They access computerized data through a limited, menu-driven environment or a strictly followed set of procedures, and use software provided by others.

They perform inquiries and simple calculations and generate unique reports for themselves. They understand the avallable databases and are able to specify, access and manipulate information.

They utilize both command and programming languages directly for their own personal information needs. They develop their own applications, some of which are used by others.

\section{FUNCTIONAL SUPPORT PERSONNEL}

They are market researchers, financial analysts, and so forth, whose primary task is providing tools to access and analyze data. By virtue of their skill in end user languages they become informal centers of systems design and programming expertise. Thus they are able to support other end-users within their functional area.

OTHER (please elaborate)

Table 3 Operationalization of IC Maturity: One Questionnaire Item

The following are five key variables that characterize information Centers (ICs). For each of the following, please indicate the one choice that best applies to your $1 C$ (Note that these questions do not pertain to the traditional information systems function of your organization, but to the $I C)$.

\section{IC Planning Procedures: For planning IC facilities and services.}

() No formal planning procedures exist.

() Formal planning procedures have been initiated.

() Formal planning procedures are well established.

() Formal planning procedures are well developed; IC planning is a part of corporate or information systems planning.

2. Control Mechanisms:

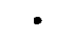

- 
instrument was not adopted for our study because the intent was to measure end-users' overall satisfaction with end-user computing. Instead, a more general measure, the short-form User Information Satisfaction (UIS) questionnaire developed by Ives et al. was modified and used for measuring end-user satisfaction [24]. The modification was done in order to adapt the instrument to the EUC context.

Using this modified instrument, end-users were asked for their perceptions on twelve factors relating to their EUC activities. A seven-point Likert-type scale was used to assess user perceptions on each factor. Table 4 summarizes the factors and the twelve scales used.

\section{Methodology and Descriptive Statistics}

THE MANAGERS OF 548 ICs IN U.S. ORGANZATIONS were identified with the help of a professional organization on the condition that it not be identified. Data on IC maturity and general IC information were collected by having IC managers respond to an executive questionnaire. Each IC manager was also requested to arrange for the participation of two users-one fairly novice user and one fairly sophisticated user. Each of the two users selected was asked to respond to an end-user questionnaire. This questionnaire was designed to collect all data specific to end-users.

\section{Survey Response}

After reminders, 114 executive questionnaires and 169 end-user questionnaires from 114 ICs were completed and returned. Another twenty-seven ICs returned their executive questionnaires but no end-user questionnaires. Yet another thirteen packets mailed were returned eithur because the IC was no longer in existence, or because it was against company policy to respond to surveys. Thus, the IC response rate for our study was $114 /(548-13) \times 100=21.3$ percent. This is quite acceptable considering the fact that the study design required multiple respondents for each IC.

\section{Response Bias Analysis}

In order to test whether the sample of respondents was representative of the population, 30 responding organizations and 30 nonresponding organizations were randomly selected from the original list of 548 organizations. These two groups were then statistically compared in terms of annual sales, number of employees, age of organization, age of the IC, number of users in the IC, size of IC staff, and IC annual budget. This information was compiled from completed questionnaires (for respondents only), Moody's Industrial Manual, Moody's Municipal \& Government Manual, Directory of Corporate Affiliations, Encyclopedia of Associations, Ward's Business Directory, and Computerworld.

The IC-specific demographic data for the sample of 30 nonresponding organizations, and some responding organizations, were not available from secondary sources and had to be gathered by phoning IC managers in each organization. Phone calls were 
Table 4 Measuring End-User Satisfaction: User Perceptions

\begin{tabular}{lrll}
\hline Perception & \multicolumn{2}{c}{ Semantic differential scale } \\
\hline Relationship with IC staff & Bad & $\ldots$ & Good \\
Communication with IC staff & Vague & $\ldots$ & Precise \\
Attitude of IC staff & Negative & $\ldots$ & Positive \\
Degree of training provided & Insufficient & $\ldots$ & Sufficient \\
Speed and quality of IC response to service & Bad & $\ldots$ & Good \\
requests & & & \\
Relevance of output & Irrelevant & $\ldots$ & Relevant \\
Accuracy of output & Inaccurate & $\ldots$ & Accurate \\
Precision of output & Imprecise & $\ldots$ & Precise \\
Completeness of output & Incomplete & $\ldots$ & Complete \\
Speed of EUC activities & Slow & $\ldots$ & Fast \\
Applications understanding & Bad & $\ldots$ & Good \\
Perceived participation in IS function & Low & $\ldots$ & High \\
\hline
\end{tabular}

also made to public relations and other departments whenever data pertaining to the organization as a whole (e.g., annual sales) were not available from secondary sources.

The statistical test used was analysis of variance (ANOVA). For each variable, the mean value for responding organizations was compared with that for nonresponding organizations. The results indicate that there are no statistically significant differences between respondents and nonrespondents with respect to all variables except "size of IC staff" (Table 5). The IC staff size was 5.71 for responding ICs and 9.93 for nonresponding ICs. Intuitively, one would expect nonrespondents to have smaller ICs. One possible explanation for the counterintuitive result is that the managers of nonresponding ICs are much busier because they have twice as many subordinates to supervise. Another possible explanation is that larger ICs may be receiving many other questionnaires and could therefore be extremely selective in responding. This latter possibility may also explain the larger average number of employees in non-responding organizations (Table 5).

It is interesting that while the IC staff figures were significantly different, the number of employees $(15,115$ versus 33,116$)$ were not found to be significantly different. This may be because of unequal variances in the two groups compared.

The tests described above suggest that the responding ICs are representative of the IC population.

\section{Organizational and IC Characteristics}

Fifty percent of the responding ICs were either in manufacturing organizations or government agencies (figure 1). Only $90 \mathrm{ICs}$ reported their annual sales. A summary of annual sales is provided in Table 6.

Table 7 summarizes responding ICs by percentiles for the number of users sup- 
Table 5 Response Bias Analysis: Demographic Data

\begin{tabular}{lrrrr} 
& & & \multicolumn{2}{c}{ Analysis of variance } \\
\cline { 4 - 5 } & Mean (resp.) & Mean (nonresp.) & \multicolumn{1}{c}{$F$} & $p$ \\
\hline Annual sales (\$ million) & $2,610.32$ & $4,680.43$ & 0.75 & 0.38 \\
No. of employe日s & $15,115.16$ & $33,116.31$ & 1.41 & 0.24 \\
Age of organization & 64.06 & 50.51 & 1.23 & 0.27 \\
(years) & & & & \\
Age of IC (years) & 3.96 & 4.75 & 1.59 & 0.21 \\
No. of users & $1,172.33$ & $1,077.06$ & 0.04 & 0.83 \\
Staff size & 5.71 & 9.93 & 4.62 & 0.03 \\
IC budget (\$ million) & 1.65 & 0.50 & 0.71 & 0.40 \\
\hline$n_{\text {respondents }}=30 ; n_{\text {nonrespondents }}=30$. & & & \\
\hline
\end{tabular}

Table 6 Annual Sales

\begin{tabular}{lcc}
\hline Sales range & No. of ICs & Percentage \\
\hline$<300$ million & 30 & $33.3 \%$ \\
300 million -599 million & 15 & $16.7 \%$ \\
600 million -999 million & 12 & $13.3 \%$ \\
1 billion $-<3$ billion & 20 & $22.2 \%$ \\
3 billion -5 billion & 2 & $2.2 \%$ \\
$>5$ billion & 11 & $12.2 \%$ \\
TOTAL & 90 & $100.0 \%$ \\
\hline
\end{tabular}

ported, number of staff, budget, and age of the IC. The numbers are similar to what previous studies have found-ICs were created less than ten years ago, the staff size for most ICs is small (less than ten), they support fairly large numbers of users, and they operate on fairly small budgets.

\section{End-User Characteristics}

As anticipated, the end-user respondents for this study were approximately evenly distributed across the four end-user categories. There were 42 nonprogramming end-users, 37 each of command-level users and end-user programmers, and 47 functional support personnel.

\section{Validation of Measures Used}

THE CONSTRUCTS OF END-USER SUPPORT and end-user satisfaction are central to the hypotheses of this study. However, the measures used for assessing them here have 


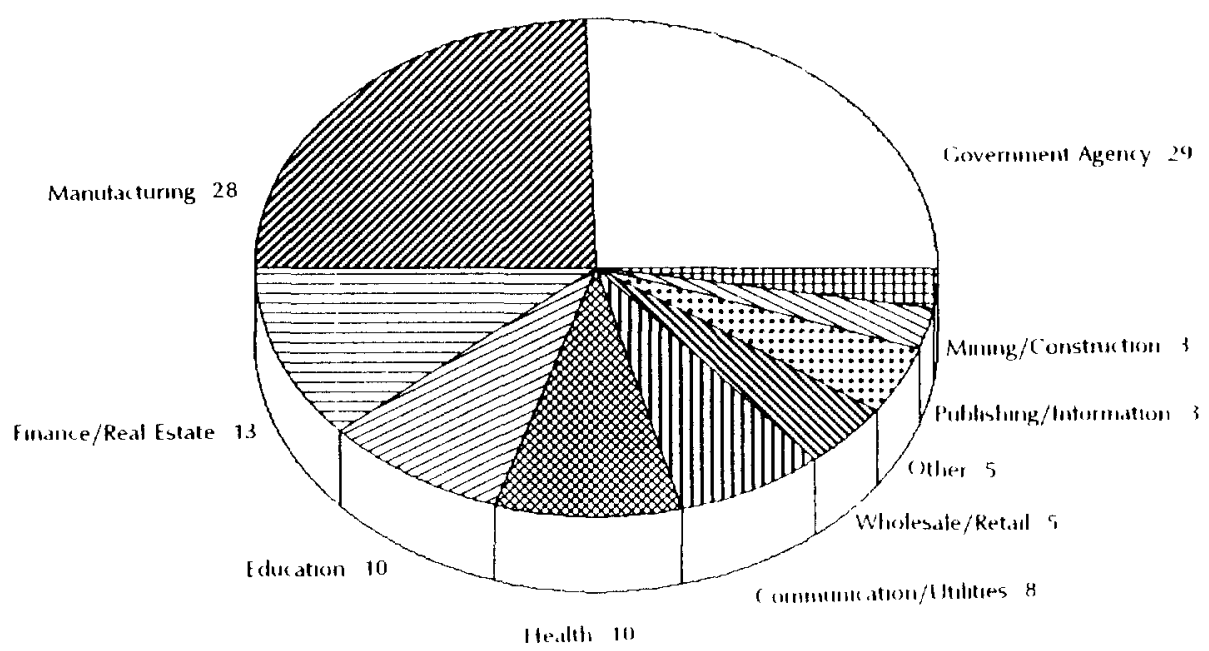

Figure 1. Responding ICs by Industry

Table 7 IC Characteristics

\begin{tabular}{lcccc}
\hline & \multicolumn{4}{c}{ IC characteristic } \\
\cline { 2 - 5 } & No. of users & No. of staff $^{1}$ & $\begin{array}{c}\text { Budget } \\
(\$ \text { million })^{2}\end{array}$ & $\begin{array}{c}\text { Age } \\
(\text { months })^{1}\end{array}$ \\
\hline 0 & 10 & 1 & 0.025 & 5 \\
25 & 250 & 3 & 0.200 & 30 \\
50 & 500 & 5 & 0.350 & 48 \\
75 & 2,000 & 9 & 0.620 & 66 \\
100 & 40,000 & 45 & 40.000 & 120 \\
\hline${ }^{1}$ Valid cases $=103$; missing cases $=12$. & & & \\
${ }^{2}$ Valid cases $=75$; missing cases $=40$. & & & \\
\hline
\end{tabular}

been previously unvalidated. Therefore, these measures were statistically analyzed in order to assess their validity and to identify the various dimensions (if any) of end-user support and end-user satisfaction. The identification of these dimensions or factors would also facilitate hypotheses testing by making it possible to examine the relationships of each dimension of a construct with other variables. Specifically, the measures of end-user support and end-user satisfaction were each subjected to factor analysis followed by reliability assessment.

\section{End-User Support}

A principal components factor analysis followed by a VARIMAX orthogonal rotation of the axes was conducted on the scales measuring support needed, to enhance 
construct validity [26]. Twelve factors with eigenvalues greater than one emerged; the extracted factors accounted for more than 71 percent of the total variance in the data. These factors were interpreted as: (1) applications development support, (2) standards and guidelines, (3) data provision support, (4) operational support, (5) purchasing-related support, (6) variety of software supported, (7) support staff characteristics, (8) postdevelopment support, (9) backups/security, (10) training on statistical analysis, (11) hardware-related services, and (12) developing macros and job control statements. Factors 10, 11, and 12 consisted of only one item each, and were dropped from the measure because their contribution to the explained variance was extremely low. The stability of factor 9 was also in question since it consisted of only two items. However, it was retained in the measure pending further analysis of its stability by means of the examination of individual item factor loadings and reliability assessment of the factor.

Of all the items in the measure, those with factor loadings greater than 0.5 were retained for further analysis; thus, of the remaining 51 items, 9 were eliminated (items $1,2,4,7,13,21,25,28$, and 52 in Table 1). Table 8 presents the remaining 42 items, their factor loadings, the eigenvalues of each factor, and the percentage of variance explained by each factor. This table also displays, for each item, its correlation with the factor it loaded on. These correlations range from 0.72 to 0.94 , and all are significant at the 0.0001 level.

Additionally, the reliability of each factor was evaluated by means of Cronbach's alpha coefficient. The values of the alpha coefficients for all factors ranged from 0.70 to 0.92 (Table 9). From these results, it was inferred that the measure of end-user support possesses construct validity. In particular, factor 9 was not dropped from the measure since there was no evidence of its instability.

An independent examination of the scree plot of eigenvalues suggested nine factors. This was consistent with the number of factors remaining after conducting the validation tests described above. Thus, the nine-factor structure for end-user support was found to be robust.

\section{End-User Satisfaction}

Once again, a principal components factor analysis followed by a VARIMAX orthogonal rotation of the axes was conducted to identify the factors in the measure used for end-user satisfaction. Three factors with eigenvalues greater than one emerged; the extracted factors accounted for more than 67 percent of the total variance in the data. These factors were interpreted as: (1) quality of IC staff, (2) quality of output from EUC, and (3) end-user competence. These factors are very similar to the three factors identified by Igbaria and Nachman [23], who used an almost identical thirteen-item instrument to measure end-user satisfaction. All twelve items had factor loadings of 0.6 or more; hence, no items were dropped from the measure. The correlations of the items with their respective factors ranged from 0.71 to 0.89 . All correlations were significant at the 0.0001 level. Once again, the reliability of each of the three factors was evaluated by means of Cronbach's alpha coefficient. These values were 0.83 , 
Table 8 Validation of Measure for End-User Support

Item Factor loading $\begin{gathered}\text { Correlation with } \\ \text { factor }\end{gathered}$

Factor 1: Applications development support (eigenvalue $=19.71$, pct. of var. $=36.5 \%$ )

Training on application testing/debugging

$0.66 \quad 0.81$

Training on application documentation

$0.74 \quad 0.84$

Training on application maintenance

$\begin{array}{ll}0.78 & 0.85\end{array}$

Training on data integrity/validation

0.67

0.78

Training on file management and database

0.50

0.73

technology

Factor 2: Standards and guidelines (eigenvalue $=3.87$, pct. of var. $=7.2 \%$ )

Standardization of programming languages

0.70

0.86

Standardization of applications development

0.73

0.87

software

Standardization of operating systems

0.83

0.82

Guidelines for systems analysis, applications,

0.64

0.81

design, testing, documentation, and

maintenance

Guidelines for software backups

0.71

0.78

Standards for data backup

0.54

0.75

Guidelines for use and modification of corporate

0.53

0.81

data

Factor 3: Data provision support (eigenvalue $=3.70$, pct. of var. $=6.9 \%$ )

Maintaining data integrity and currency

0.60

0.72

Providing data backup/recovery service

0.61

0.74

Listing corporatewide data resources

0.71

0.77

Providing corporate data extraction facilities

0.64

0.80

Facilitating data sharing among users

0.73

0.83

Maintaining subject databases

0.65

0.76

Factor 4: Operational support (eigenvalue $=2.08$, pet. of var. $=3.9 \%$ )

Training on application selection and cost

0.65

0.74 justification

Training on tool/product selection

0.65

0.76

Training on data communications

0.59

0.77

Training on operating systems

0.71

0.79

Training on software conversions

0.54

0.73

Technology updates

0.76

0.79

Listing software resources: software libraries

0.53

0.74 
Table 8 Continued

\begin{tabular}{lcc}
\hline Item & Factor loading & $\begin{array}{c}\text { Correlation with } \\
\text { factor }\end{array}$ \\
\hline Factor 5: Purchasing related support (eigenvalue & $=1.97$, & pct. of var. $=3.7 \%$ ) \\
Standardization of hardware to be used & 0.55 & 0.80 \\
Listing approved hardware vendors & 0.88 & 0.89 \\
Outlining formal procedures for getting hardware & 0.82 & 0.88 \\
purchase approved & & \\
Establishment of communication protocols & 0.72 & 0.85 \\
Listing approved software vendors & 0.68 & 0.82 \\
Outlining formal procedures for getting software & 0.65 & 0.85
\end{tabular}

purchase approved

Factor 6: Variety of software supported (eigenvalue $=1.80$, pct. of var. $=3.3 \%$ )

Supporting 4GLs

$\begin{array}{ll}0.61 & 0.88 \\ 0.67 & 0.88 \\ 0.70 & 0.84\end{array}$

Supporting a variety of other languages

$0.70 \quad 0.84$

Factor 7: Support staff characteristics (eigenvalue $=1.69$, pct. of var. $=3.1 \%$ )

Delineation of end-user and staff roles

$\begin{array}{ll}0.60 & 0.81 \\ 0.78 & 0.83 \\ 0.67 & 0.78\end{array}$

Specialization of support staff

Factor 8: Postdevelopment support (eigenvalue $=1.51$, pct. of var. $=2.8 \%$ )

$\begin{array}{lll}\text { Auditing user-developed applications } & 0.65 & 0.94 \\ \text { Conducting maintenance reviews of } & 0.59 & 0.94\end{array}$
user-developed applications

$\begin{array}{lll}\text { Coordinating applications across users } & 0.54 & 0.89\end{array}$

Factor 9: Backups/security (eigenvalue $=1.30$, pct. of var. $=2.4 \%$ )

Training on backups/security

$0.71 \quad 0.87$

Providing software backup/recovery service

$0.52 \quad 0.88$

Factor 10: Training on statistical analysis ${ }^{2}$

0.82

(eigenvalue $=1.16$, pct. of var. $=2.2 \%$ )

Factor 11: Hardware-related services ${ }^{2} \quad 0.79$

(eigenvalue $=1.14$, pct. of var. $=2.1 \%$ )

$-$

Factor 12: Developing macros and job control $\quad 0.66$ statements ${ }^{2}$ (eigenvalue $=1.07$,

$-$ pct. of var. $=2.0 \%$ )

${ }_{1}$ All coefficients are significant at the 0.0001 level.

${ }^{2}$ These factors were dropped from the measure. 
Table 9 Factors of Support: Internal Consistency

\begin{tabular}{|c|c|c|}
\hline Scale & Number of items & Cronbach's $\alpha$ \\
\hline Applications development support & 5 & 0.85 \\
\hline Standards and guidelines & 7 & 0.91 \\
\hline Data provision support & 6 & 0.86 \\
\hline Operational support & 7 & 0.88 \\
\hline Purchasing-related support & 6 & 0.92 \\
\hline Variety of software supported & 3 & 0.83 \\
\hline Support staff characteristics & 3 & 0.72 \\
\hline Postdevelopment support & 3 & 0.91 \\
\hline Backups/security & 2 & 0.70 \\
\hline Training on statistical analysis ${ }^{1,2}$ & 1 & - \\
\hline Hardware-related services ${ }^{1,2}$ & 1 & - \\
\hline Developing macros and job control statements ${ }^{1,2}$ & 1 & - \\
\hline
\end{tabular}

0.88 , and 0.62 , respectively. From these results, it was inferred that the measure of end-user satisfaction possesses construct validity. Table 10 summarizes the relevant data.

\section{Results}

\section{End-User Computing Sophistication and Support Needed}

NULL HYPOTHESIS 1 STATES THAT SUPPORT NEEDED by end-users does not vary significantly with end-user computing sophistication. To test this using the first operationalization of end-user computing sophistication, the mean scores for each of the nine factors were compared across the four user categories by means of nine ANOVAs. For five of the nine factors, the differences between the mean scores of the four user categories were statistically significant at the 0.05 level. These factors were: standards and guidelines, data provision support, purchasing-related support, variety of software supported, and postdevelopment support. For these five factors, support needed increased uniformly and fairly steeply along the end-user spectrum, from nonprogramming end-users to functional support personnel. Following the ANOVA, several $t$-tests were conducted to compare the factor means across pairs of user categories. The results of the ANOVA and the $t$-tests are presented in Tables 11 and 12 , respectively.

Null Hypothesis 1 was also tested using the second operationalization of end-user computing sophistication. For each of the nine factors of support, a Student's $t$-test was used to examine whether the differences between the mean scores of application developers and nondevelopers were statistically significant. 
Table $10 \quad$ Validation of Measure for End-User Satisfaction

\begin{tabular}{|c|c|c|}
\hline Item & Factor loading & $\begin{array}{c}\text { Correlation with } \\
\text { factor }^{1}\end{array}$ \\
\hline \multicolumn{3}{|c|}{ Factor 1: Quality of $I C$ staff (eigenvalue $=5.32$, pct. of var. $=44.3 \%$ ) } \\
\hline Relationship with IC staff & 0.82 & 0.77 \\
\hline Communication with IC staff & 0.83 & 0.81 \\
\hline Attitude of IC staff & 0.82 & 0.79 \\
\hline Degree of training provided & 0.60 & 0.77 \\
\hline $\begin{array}{l}\text { Speed and quality of response to requests for } \\
\text { service }\end{array}$ & 0.68 & 0.80 \\
\hline \multicolumn{3}{|c|}{ Factor 2: Quality of output from EUC (eigenvalue $=1.70$, pct. of var. $=14.2 \%$ ) } \\
\hline Relevance of output from computing activities & 0.71 & 0.81 \\
\hline Accuracy of output from computing activities & 0.88 & 0.86 \\
\hline Precision of output from computing activities & 0.89 & 0.89 \\
\hline Completeness of output from computing activities & 0.79 & 0.86 \\
\hline \multicolumn{3}{|c|}{ Factor 3: End-user competence (eigenvalue $=1.13$, pct. of var. $=9.4 \%$ ) } \\
\hline $\begin{array}{l}\text { Speed with which you are able to carry on your } \\
\text { computing activities }\end{array}$ & 0.62 & 0.71 \\
\hline Your understanding of the applications you use & $0 ; 76$ & 0.74 \\
\hline $\begin{array}{l}\text { Your perceived participation in the information } \\
\text { systems function }\end{array}$ & 0.75 & 0.82 \\
\hline
\end{tabular}

The results of these analyses are presented in Table 13. Applications developers perceive greater needs than nondevelopers for all nine factors of support. For five of these nine factors, the differences in needs be $:$ ween developers and nondevelopers are statistically significant at the 0.05 level. These factors are: applications development support, standards and guidelines, data provision support, support staff characteristics, and postdevelopment support.

From all these results, Null Hypothesis 1 is strongly rejected, with the implication that support needed varies greatly with end-user computing sophistication.

\section{IC Maturity and Support Needed}

Null Hypothesis 2 states that support needed by end-users does not vary significantly with IC maturity. To test this, correlations between each factor of support and IC maturity were examined separately under each of the four user categories. The results of these 36 correlations are extremely interesting. For nonprogramming end-users and command-level users, none of the correlations between IC maturity and the factors of support are significant at the 0.05 level. On the other hand, seven of the nine correlations are significantly and strongly positive for end-user programmers. The two 
Table 11 User Categories versus Support Needed

\begin{tabular}{|c|c|c|c|c|c|c|}
\hline \multirow[t]{2}{*}{ Factor of support } & \multicolumn{4}{|c|}{ Mean score } & \multicolumn{2}{|c|}{ ANOVA } \\
\hline & Non. & Comm. & Prog. & Func. & $F$ & $p$ \\
\hline $\begin{array}{l}\text { Applications } \\
\text { development support }\end{array}$ & 4.19 & 4.80 & 4.98 & 4.82 & 2.03 & 0.11 \\
\hline $\begin{array}{l}\text { Standards and } \\
\text { guidelines }\end{array}$ & 3.55 & 4.15 & 4.59 & 4.84 & 4.68 & 0.00 \\
\hline Data provision support & 3.98 & 4.57 & 5.02 & 5.26 & 5.76 & 0.00 \\
\hline Operational support & 4.06 & 4.71 & 4.52 & 4.82 & 2.29 & 0.07 \\
\hline $\begin{array}{l}\text { Purchasing-related } \\
\text { support }\end{array}$ & 3.85 & 4.58 & 4.12 & 4.84 & 2.75 & 0.04 \\
\hline $\begin{array}{l}\text { Variety of software } \\
\text { supported }\end{array}$ & 3.26 & 3.58 & 3.97 & 4.42 & 3.22 & 0.02 \\
\hline $\begin{array}{l}\text { Support staff } \\
\text { characteristics }\end{array}$ & 4.89 & 4.99 & 5.44 & 5.33 & 1.39 & 0.24 \\
\hline $\begin{array}{l}\text { Postdevelopment } \\
\text { support }\end{array}$ & 2.83 & 3.88 & 3.73 & 4.22 & 4.08 & 0.00 \\
\hline Backups/security & 4.89 & 5.22 & 5.00 & 4.94 & 0.27 & 0.84 \\
\hline
\end{tabular}

Bold $p$ values indicate significant differences at the 0.05 level.

Key: Nonprog. = nonprogramming end-users; Command. = command-level users;

Prog. = End-user programmers; Func. = functional support personnel.

Table 12 Support Needed, Compared across Pairs of User Categories

User categories compared pairwise

Nonprogramming end-users with command-level users

Nonprogramming end-users with end-user programmers

End-user programmers with functional support personnel

Command-level users with functional support personnel

Nonprogramming end-users with functional support personnel
Factors with significantly different means

$(p<0.05)$
Applications development support, standards and guidelines, data provision support, postdevelopment support

Purchasing-related support

Standards and guidelines, data provision support, variety of software supported

Standards and guidelines, data provision support, operational support, purchasingrelated support, variety of software supported, postdevelopment support 
Table 13 Applications Development versus Support Needed

\begin{tabular}{lcccc}
\hline \multirow{2}{*}{ Factor of support } & \multicolumn{2}{c}{ Mean score } & \multicolumn{2}{c}{$t$-test } \\
\cline { 2 - 5 } & $\begin{array}{c}\text { Application } \\
\text { developers }\end{array}$ & $\begin{array}{c}\text { Non- } \\
\text { developers }\end{array}$ & $t$ & $p^{*}$ \\
\hline Applications development support & 4.92 & 4.45 & 1.91 & 0.02 \\
Standards and guidelines & 4.66 & 3.97 & 2.67 & 0.00 \\
Data provision support & 5.00 & 4.43 & 2.39 & 0.00 \\
Operational support & 4.62 & 4.46 & -0.70 & 0.24 \\
Purchasing-related support & 4.44 & 4.32 & -0.43 & 0.30 \\
Variety of software supported & 4.02 & 3.70 & 1.11 & 0.13 \\
Support staft characteristics & 5.35 & 5.00 & 1.63 & 0.05 \\
Postdevelopment support & 3.97 & 3.41 & 1.86 & 0.03 \\
Backups/security & 5.01 & 5.00 & -0.02 & 0.49 \\
\hline
\end{tabular}

* 1-tailed $t$-test.

Bold $p$ values indicate significant differences at the 0.05 level.

correlations that are not significant are for applications development support and support staff characteristics. Finally, only two of the nine correlations are significant and positive for functional support personnel. These are for standards and guidelines and postdevelopment support. Table 14 presents all the data.

Null Hypothesis 2 is therefore rejected in the context of sophisticated end-users, particularly for end-user programmers. Among these kinds of users, support needed is much higher in more mature ICs. However, Null Hypothesis 2 cannot be rejected for novice and less sophisticated users, with the implication that for these types of users, support needed does not vary with IC maturity.

\section{Support Provided versus Support Needed}

Null Hypothesis 3 states that support provided to users is not significantly different from the support needed by them. To examine whether ICs fulfill their end-users' support needs, the differences between support needed and support provided for each factor were computed separately for all four user categories. A bar graph depicts these differences in figure 2.

Many interesting observations follow from this graph. First, the differences between support needed and support provided are almost always positive, indicating that the perceived extent of support provided is almost always less than the support needed. This supports the findings of a recent study that ICs are not responsive to end-user needs [43].

The graph suggests that the difference between support needed and support provided increases with user sophistication for all nine factors. Since user needs for support were earlier shown to increase with end-user computing sophistication, this also 
Table 14 Pearson Correlations of IC Maturity with Factors of Support Needed, by End-User Categories

\begin{tabular}{lcccc}
\hline \multirow{2}{*}{ Factor of support } & \multicolumn{4}{c}{ Correlation coefficient, significance } \\
\cline { 2 - 5 } & Nonprog. & Command. & Prog. & Func. \\
\hline Applications development support & 0.17 & -0.06 & 0.25 & 0.01 \\
& $(0.13)$ & $(0.35)$ & $(0.06)$ & $(0.45)$ \\
Standards and guidelines & 0.07 & 0.01 & 0.36 & 0.26 \\
& $(0.33)$ & $(0.46)$ & $(0.01)$ & $(\mathbf{0 . 0 3})$ \\
Data provision support & 0.22 & 0.00 & 0.32 & -0.15 \\
& $(0.08)$ & $(0.48)$ & $(0.02)$ & $(0.15)$ \\
Operational support & 0.06 & -0.09 & 0.27 & -0.05 \\
& $(0.33)$ & $(0.30)$ & $(0.05)$ & $(0.36)$ \\
Purchasing-related support & 0.00 & -0.09 & 0.32 & 0.12 \\
& $(0.49)$ & $(0.29)$ & $(0.02)$ & $(0.19)$ \\
Variety of software supported & -0.01 & -0.15 & 0.35 & 0.08 \\
& $(0.45)$ & $(0.19)$ & $(0.01)$ & $(0.29)$ \\
Support staft characteristics & 0.08 & -0.05 & 0.18 & 0.20 \\
& $(0.29)$ & $(0.37)$ & $(0.14)$ & $(0.08)$ \\
Postdevelopment support & 0.08 & -0.10 & 0.42 & 0.26 \\
& $(0.31)$ & $(0.26)$ & $(0.00)$ & $(0.03)$ \\
Backups/security & 0.08 & -0.19 & 0.31 & 0.03 \\
& $(0.29)$ & $(0.13)$ & $(0.02)$ & $(0.39)$ \\
\hline
\end{tabular}

Bold $p$ values indicate correlations significant at the 0.05 level.

Key: Nonprog. = nonprogramming end-users; Command. = command-level users; Prog. = enduser programmers; Func. $=$ functional support personnel.

suggests that the extent of support provided by ICs does not increase with end-user computing sophistication. This implication was tested by comparing support provided across the four user categories, for each of the nine factors of support. Nine ANOVAs were conducted for this purpose. These ANOVAs revealed that for each of the nine factors of support, there were indeed no significant differences in the support provided across the four categories of end-users (Table 15).

Null Hypothesis 3 is therefore rejected, with the implication that the amount of support provided to end-users is significantly less than the amount of support needed by them.

\section{Support and End-User Satisfaction}

Null Hypothesis 4 states that end-user satisfaction does not vary significantly with fulfillment of support needs. To test this hypothesis, "fulfillment of support needs" needs to be defined first. For each of the nine support factors, this was defined and computed as follows: 


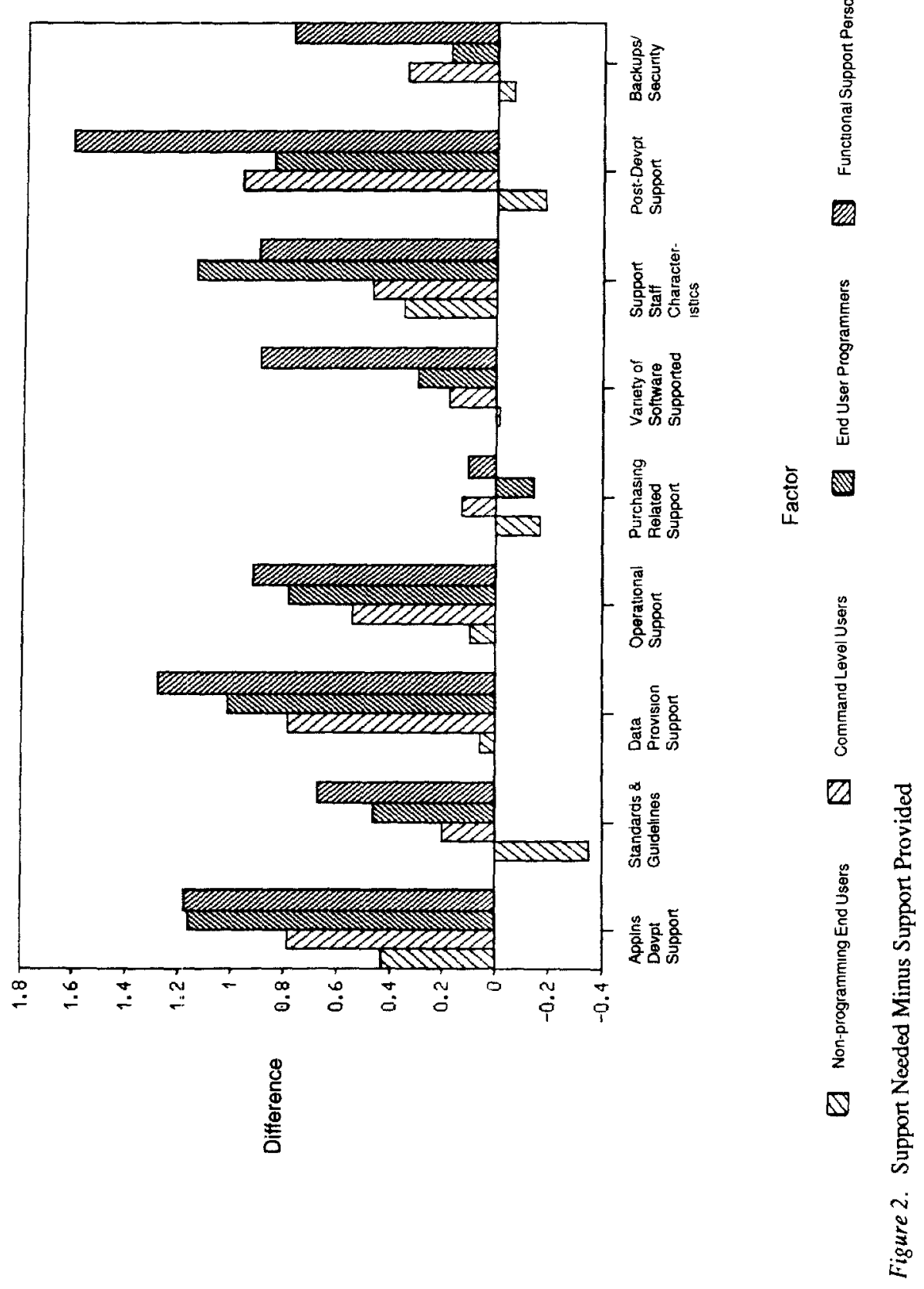


Table 15 User Categories versus Support Provided

\begin{tabular}{|c|c|c|c|c|c|c|}
\hline \multirow[t]{2}{*}{ Factor of support } & \multicolumn{4}{|c|}{ Mean score } & \multicolumn{2}{|c|}{ ANOVA } \\
\hline & Non. & Comm. & Prog. & Func. & $F$ & $p$ \\
\hline $\begin{array}{l}\text { Applications } \\
\text { development support }\end{array}$ & 3.71 & 4.01 & 3.83 & 3.64 & 0.43 & 0.72 \\
\hline $\begin{array}{l}\text { Standards and } \\
\text { guidelines }\end{array}$ & 4.10 & 3.86 & 4.13 & 4.16 & 0.32 & 0.80 \\
\hline Data provision support & 3.87 & 3.72 & 4.01 & 3.97 & 0.24 & 0.86 \\
\hline Operational support & 3.91 & 4.18 & 3.69 & 3.89 & 0.62 & 0.59 \\
\hline $\begin{array}{l}\text { Purchasing-related } \\
\text { support }\end{array}$ & 4.09 & 4.36 & 4.26 & 4.73 & 1.20 & 0.31 \\
\hline $\begin{array}{l}\text { Variety of software } \\
\text { supported }\end{array}$ & 3.44 & 3.34 & 3.70 & 3.51 & 0.26 & 0.84 \\
\hline $\begin{array}{l}\text { Support staff } \\
\text { characteristics }\end{array}$ & 4.64 & 4.42 & 4.29 & 4.42 & 0.36 & 0.77 \\
\hline $\begin{array}{l}\text { Postdevelopment } \\
\text { support }\end{array}$ & 3.07 & 2.86 & 2.83 & 2.67 & 0.35 & 0.78 \\
\hline Backups/security & 4.95 & 4.86 & 4.76 & 4.17 & 1.80 & 0.14 \\
\hline
\end{tabular}

Key: Nonprog. = nonprogramming end-users; Command. = command-level users; Prog. = enduser programmers; Func. $=$ functional support personnel.

$$
F=1-\frac{\sum\left[\left(\left(N_{i}-P_{i}\right)+\left|N_{i}-P_{i}\right|\right) / N_{i}\right]}{2 n}
$$

where $F=$ the proportion of an end-user's needs for a factor of support that have been fulfilled by the IC; $N_{i}=$ an end-user's perceived need for an item of support; $P_{i}=$ an end-user's perception of the extent to which the IC provides him or her this item of support, and $n=$ total number of support items constituting the factor of support in question.

In the above equation, for each item under a factor of support, support provided is subtracted from support needed. This yields an end-user's unfulfilled need for that support item. This difference is divided by support needed, yielding the unfulfilled proportion of the end-user's need for that item. This proportion is then averaged over all items that constitute a factor of support. This yields the aggregate proportion of unfulfilled needs for that factor. Finally, "fulfillment of support needs" for the factor is computed as one minus this aggregate proportion.

For any item, if the support provided exceeds support needed, the difference must be treated as zero instead of a negative quantity because needs unfulfilled cannot be negative, by definition. This is mathematically represented in the equation by adding 
the difference to the absolute value of the difference and dividing the total by two.

To test Null Hypothesis 4, Pearson correlations of end-user satisfaction with "fulfillment of support needs" were conducted separately for each of the nine support factors. It is clear from the results of these analyses that there are strong and positive correlations between "fulfillment of support needs" and end-user satisfaction. All nine correlations are significant at the 0.001 level. Null Hypothesis 4 is therefore strongly rejected. The results of these nine correlation analyses are summarized in Table 16.

\section{Discussion of Results}

\section{Implications for IS Practice}

END-USER SATISFACTION HAS BEEN FOUND TO BE HIGHER if more end-user support needs are fulfilled. Also, end-users' needs were seen to vary with the computing sophistication of users. The single most important implication of these findings for IC managers is that support services should be designed around the needs of end-users. IC staffs should put more effort into understanding the business functions of their end-users. This will enable them to better grasp end-users' support needs.

This study showed that although end-users' support needs vary with their computing sophistication, IC staffs tend to provide all their users with the same levels of support. This suggests that IC staffs are either unaware of differential needs of end-users or are unable to address them because of scant resources. Another possible explanation may be that sophisticated users often know more than the IC staff and possess such advanced skills with specific tools that IC staff cannot possibly meet their specialized needs.

A major part of any solution to this problem lies in educating senior management and IS management alike. The lesson for senior managers is that the allocation of adequate resources for the management of EUC is necessary to prevent dysfunctional consequences for the organization. The lesson for IS managers is that the successful management of EUC requires careful planning on their part |29]. Specifically, IC staffs must discard the notion that the support needs of all end-users are the same. They must learn to identify differences among end-users, anticipate differential support needs, and address them on a proactive basis. In organizations where IC staff do not possess the requisite skills to assist highly advanced users, the formation of user groups should be facilitated by the IC staff so that users with similar support needs can assist each other.

\section{Implications for IS Research}

This study has found that end-user computing sophistication and IC maturity are positively associated with end-user support. Future studies could try to replicate this research by using different research designs. For instance, a random selection of end-users from the population of end-users in each IC would allow researchers to draw 
Table 16 Correlations of End-User Satisfaction with "Fulfillment of Support Needs"

\begin{tabular}{lcc}
\hline Factor of support & Correlation coefficient & Significance $(p)$ \\
\hline Applications development support & 0.32 & 0.00 \\
Standards and guidelines & 0.19 & 0.00 \\
Data provision support & 0.26 & 0.00 \\
Operational support & 0.31 & 0.00 \\
Purchasing-related support & 0.21 & 0.00 \\
Variety of software supported & 0.29 & 0.00 \\
Support staft characteristics & 0.37 & 0.00 \\
Postdevelopment support & 0.28 & 0.00 \\
Backups/security & 0.22 & 0.00 \\
\hline
\end{tabular}

conclusions regarding the impact of IC maturity on end-user support with greater confidence. A random selection of end-users would also eliminate sources of possible bias in this study. One such possible bias is that IC managers may have selected only extremely satisfied end-users. Another is that IC managers may have varied in their criteria for determining who is a sophisticated or unsophisticated user.

The constructs of end-user computing sophistication and IC maturity may be operationalized differently to test whether the findings of this study hold up under other operational definitions of these constructs. In particular, having the IC managers themselves determine the maturity of their own IC based upon their responses to the five "key variables" has its drawbacks. Independent judges could provide more valid assessments than self reports from IC managers.

Future research could further develop and refine the measure of end-user support used in this study, and perform additional validation tests such as convergent and discriminant validity by using a multitrait-multimethod matrix [11].

Future research could also follow up on the conclusions of this study by examining whether end-users' support needs vary with other constructs. Examples of such constructs are the types of user-developed applications, hardware used, and so on. One possible avenue of exploration is to draw upon available research in organizational theory to identify other such constructs. Exploratory interviews with end-users and staffs in ICs may be used to identify other such constructs.

The rejection of Null Hypothesis 4 lends further credence to the conclusions of previous empirical studies (described in the literature review) that users' satisfaction is enhanced when their support needs are met. However, surrogates of EUC effectiveness other than end-user satisfaction may be used to test the extent to which end-user support actually benefits the organization. Examples of altemative surrogates that 
could be used are time and money savings, productivity increases [16], and application utilization [4].

\section{REFERENCES}

1. Alavi, M.; Nelson, R.R.; and Weiss, I.R. Strategies for end-user computing: an integrative framework. Journal of Management Information Systems, 4, 3 (1987), $29-49$.

2. Alavi, M.; Nelson, R.R.; and Weiss, I.R. Managing end-user computing as a value-added resource. Journal of Information Systems Management, 5, 3 (1988), 26-35.

3. American Management Association. AMA Report on End-User and Departmental Computing. New York: AMA Membership Publications, 1988.

4. Amoroso, D.L., and Cheney, P.H. Testing a causal model of end-user application effectiveness. Journal of Management Information Systems, 8, 1 (1991), 63-89.

5. Arkush, E., and S.A. Stanton. Third-era information systems: strategy development continued. Journal of Information Systems Management, 4, 2 (1987), 66-69.

6. Amoudse, D.M., and Oullette, L.P. An introduction to the information center concept. Information Strategy, 3, 2 (1986), 9-12.

7. Benson, D.H. A field study of end user computing: findings and issues. MIS Quarterly, 7, $4(1983), 35-45$.

8. Bergeron, F., and Berube, $C$. The management of the end-user environment: an empirical investigation. Information and Management, 14, 2 (1988), 107-113.

9. Bergeron, F.; Rivard, S.; and De Serre, L. Investigating the support role of the information center. MIS Quarterly, 14, 3 (1990), 247-260.

10. Brancheau, J.C.; Vogel, D.R.; and Wetherbe, J.C. An investigation of the information center from the user's perspective. Data Base, 17, 1 (Fall 1985), 4-17.

11. Campbell, D.T., and Fiske, D.W. Convergent and discriminant validation by the multitrait-multimethod matrix. Psychological Bulletin, 56 (March 1959), 81-105.

12. Carr, H.H. Information centers: the IBM model vs. practice. MIS Quarterly, 11,3 (1987), 325-338.

13. Caudle, S.L.; Gorr, W.L.; and Newcomer, K.E. Key information systems management issues for the public sector. MIS Quarterly, 15, 2(1991), 171-188.

14. Christy, D.P., and White, Jr., C.E. Structure and function of information centers: case studies of six organizations. Information and Management, 13, 2 (1987), 71-76.

15. Cotterman, W.W., and Kumar, K. User cube: a taxonomy of end users. Communications of the ACM, 32, 11 (1989), 1313-1320.

16. Cronan, T.P., and Douglas, D.E. End-user training and computing effectiveness in public agencies: an empirical study. Journal of Management Information Systems, 6, 4 (Spring 1990), $21-39$.

17. Davis, J.G. A Typology of Information Systems Users and its Implications for Effectiveness Research. Unpublished Ph.D. dissertation, University of Pittsburgh, 1986.

18. Doll, W.J., and Torkzadeh. G. The measurement of end-user computing satisfaction. MIS Quarterly, 12, 2 (1988), 259-274.

19. Galletta, D.F., and Lederer, A.L. Some cautions on the measurement of user information satisfaction. Decision Sciences, 20, 3 (Summer 1989), 419-438.

20. Hammond, L.W. Management considerations for an information center. IBM Systems Journal, 21, 2 (1982), 131-161.

21. Henderson, J.C., and Treacy, M.E. Managing end-user computing for competitive advantage. Sloan Management Review, 27, 2 (1986), 3-13.

22. Huff, S.L.; Munro, M.C.; and Martin, B.H. Growth stages of end user computing. Communications of the ACM, 31, 5 (1988), 542-550.

23. Igbaria, M., and Nachman, S.A. Correlates of user satisfaction with end user computing: an explor atory study. Information and Management, 19, 2(1990), 73-82.

24. Ives, B.; Olson, M.H.; and Baroudi, J.J. The measurement of user information satisfaction. Communications of the ACM, 26, 10 (1983), 785-793.

25. Kasper, G.M., and Cervany, R.P. A laboratory study of user characteristics and decisionmaking performance in end-user computing. Information and Managemens, 9, 2 (1985), 87-96. 
26. Kerlinger, F.N. Foundations of Behavioral Research. New York: Holt, Rinehart, and Winston, 1973.

27. Kleinberg, E.R. Strategies for effective microcomputer management. Journal of Information Systems Management, 3, 1 (1986), 27-35.

28. Kwan, S.K., and Curley, K.F. Corporate MIS/DP and end-user computing: the emergence of a new partnership. Data Base, 20, 2 (1989), 31-37.

29. Lederer, A.L., and Sethi, V. Planning for end-user computing: top-down or bottom-up? Information Management Review, 2, 2 (1986), 25-34.

30. Lederer, A.L., and Spencer, V.L. The effective information center: targeting the individual user for success. Journal of Systems Management, 39, 1 (January 1988), 22-26.

31. Leitheiser, R.L., and Wetherbe, J.C. Service support levels: an organized approach to end-user computing. MIS Quarterly, 10, 4 (1986), 337-349.

32. Loevinger, J. Objective tests as instruments of psychological theory. Psychological Reports, 3, (1957), 635-694.

33. Magal, S.R. The evolution of information centers: a stage hypothesis. Data Base, 20, 1 (1989), 39-46.

34. Magal, S.R., and Carr, H.H. An investigation of the effects of age, size, and hardware option on the critical success factors applicable to information centers. Journal of Management Information Systems, 4, 4 (1988), 60-76.

35. Magal, S.R.; Carr, H.H.; and Watson, H.J. Critical success factors for information center managers. MIS Quarterly, 12, 3 (1988), 413-425.

36. McLean, E.R. End users as application developers. MIS Quarterly, 3, 3 (1979), 37-46.

37. Munro, M.C.; Huff, S.L.; and G. Moore. Expansion and control of end-user computing. Journal of Management Information Systems, 4, 3 (1987-88), 5-27.

38. Necco, C.R.; Gordon, C.L.; and Tsai, N.W. The information center approach for developing computer-based information systems. Information and Management, 13, 2 (1987), $95-101$.

39. Nelson, R.R., and Cheney, P.H. Training end-users: an exploratory study. MIS Quarterly, 11,4 (1987), 547-559.

40. O'Donnell, D.J., and March, S.T. End-user computing environments-finding a balance between productivity and control. Information and Management, 13, 2 (1987), 77-84.

41. Panko, R.R. Directions and issues in end user computing. Information Systems and Operations Research, 25, 3 (1987), 181-197.

42. Porter, L.R., and Gogan, J.L. Coming to terms with end-user systems integration. Journal of Information Systems Management, 5, 1 (1988), 8-16.

43. Rainer, Jr., R.K., and Carr, H.H. Are information centers responsive to end user needs? Information and Management, 22 (1992), 113-121.

44. Rivard, S. Successful implementation of end-user computing. Interfaces, 17, 3 (1987), $25-33$.

45. Rivard, S., and Huff, S.L. User developed applications: evaluations of success from the DP department perspective. MIS Quarterly, 8, 1 (1984), 39-49.

46. Rivard, S., and Huff, S.L. An empirical study of users as application developers. Information and Management, 8, 2 (1985), 89-102.

47. Rockart, J.F., and Flannery, L.S. The management of end user computing. Communications of the ACM, 26, 10 (1983), 776-784.

48. Srinivasan, A. Alternative measures of systems effectiveness: associations and implications. MIS Quarterly, 9, 3 (1985), 243-253.

49. Steele, J., and Botomley, D. Channeling the end-user computing initiative: a case study. Journal of Information Systems Management, 5, 2 (1988), 49-55.

50. White, Jr., C.E., and Christy, D.P. The information center concept: a normative model and a study of six installations. MIS Quarterly, 7, 4 (1987), 451-458. 